\title{
Columnar-lined Esophagus: Its Prevalence and Predictors in Patients With Gastroesophageal Reflux Disease
}

(Am J Gastroenterol 2012;107:1655-1661)

\section{Gwang Ha Kim}

Department of Internal Medicine, Pusan National University School of Medicine, Busan, Korea

\section{Summary}

The prevalence of Barrett's esophagus has varied based on the study population diversity and the definition of Barrett's esophagus used. Because intestinal metaplasia in the distal esophagus predisposes to esophageal adenocarcinoma, Barrett's esophagus is defined as a condition in which normal stratified squamous epithelium is replaced by metaplastic columnar epithelium in the distal esophagus with histopathological evidence of intestinal metaplasia. ${ }^{1}$ However in other areas (UK and Asia), Barrett's esophagus is diagnosed solely based on the presence of columnar-lined esophagus (CLE) on endoscopy without the need to document intestinal metaplasia. ${ }^{2,3}$ This definition has been supported by some previous studies suggesting comparable cancer risk among those with CLE with and without intestinal metaplasia, and sampling error to identify goblet cells. ${ }^{4,5}$ Recently, Balasubramanian et $\mathrm{al}^{6}$ conducted a prospective study on 1,058 subjects with gastroesophageal reflux disease (GERD) to evaluate the prevalence and predictors of CLE. In this study, the prevalence of CLE was $23.3 \%$, whereas of CLE with docu- mented intestinal metaplasia was $14.1 \%$. By time trend analysis, there was no significant changes in the prevalence of CLE over the study period. On univariate analysis, male gender, Caucasian race, heartburn duration $>5$ years, presence and size of hiatal hernia were significantly associated with the presence of CLE. On multivariate analysis, heartburn duration $>5$ years $(\mathrm{OR}$, $1.50 ; 95 \% \mathrm{CI}, 1.07-2.09)$, Caucasian race (OR, 2.40; 95\% CI, 1.42-4.03), and hiatal hernia (OR, 2.07; 95\% CI, 1.50-2.87) were found to be independent predictors for CLE. Therefore, they concluded that if $\mathrm{BE}$ is defined by the presence of CLE alone on upper endoscopy, up to $25 \%$ of GERD patients would be diagnosed with this lesion, and enrolling all these patients in surveillance programs would have significant ramifications on health-care resources.

\section{Comments}

Long-standing GERD is considered as one of the risk factors for Barrett's esophagus, which is the only known premalignant condition for esophageal adenocarcinoma. ${ }^{1,5}$ However, the current clinical practice and management of Barrett's esophagus

Received: January 15, 2013 Revised: January 23, 2013 Accepted: January 24, 2013

(c) This is an Open Access article distributed under the terms of the Creative Commons Attribution Non-Commercial License (http://creativecommons. org/licenses/by-nc/3.0) which permits unrestricted non-commercial use, distribution, and reproduction in any medium, provided the original work is properly cited.

*Correspondence: Gwang Ha Kim, MD

Department of Internal Medicine, Pusan National University School of Medicine and Biomedical Research Institute, Pusan National University Hospital, 179, Gudeok-ro, Seo-gu, Busan 602-739, Korea

Financial support: None. Tel: +82-51-240-7869, Fax: +82-51-244-8180, E-mail: doc0224@pusan.ac.kr

Conflicts of interest: None. 
is poorly standardized outside of clinical trials. ${ }^{7}$ The way diagnosing Barrett's esophagus has important implications in defining the disease burden and risk stratification for cancer. Older studies had estimated a 30 to 125 -fold higher risk for cancer in patients with intestinal metaplasia, ${ }^{8}$ but a recent large multicenter study showed that only 18 developed incidence of cancer $(0.27 \%$ per year; 95\% CI, 0.17-0.43) in a large cohort of 1,204 patients with non-dysplastic CLE with intestinal metaplasia. ${ }^{9}$ Considering the estimated cancer risk being low in those with intestinal metaplasia, the cancer risk among those with CLE alone could be much lower. In fact, in a recent Irish study, the cancer risk was significantly higher among those with CLE with intestinal metaplasia than those with CLE with no intestinal metaplasia $(0.38 \%$ per year vs. $0.07 \%$ per year, $P<0.001){ }^{2}$

In this study, CLE alone (without intestinal metaplasia) was associated with shorter lengths $(<1 \mathrm{~cm})$. The positive correlations between CLE length and the risk of cancer have been reported in a recent meta-analysis ${ }^{10}$; the annual incidence of cancer among patients with Barrett's esophagus (all lengths) was $0.33 \%$, whereas the risk for cancer was lower among those with shorter segment Barrett's esophagus of $<3 \mathrm{~cm}$ (annual incidence of $0.19 \%$ ). Also, the poor reliability in making diagnosis of Barrett's esophagus among those with CLE length $<1 \mathrm{~cm}$ has also been well documented (reliability coefficient $=0.22) .{ }^{11}$ Therefore, the diagnosis of Barrett's esophagus should be cautioned in those with shorter lengths of CLE.

Although no association between duration of reflux and CLE with intestinal metaplasia was reported in some studies, ${ }^{9}$ most studies including this study proved that there is a linear relationship between the risk of CLE with intestinal metaplasia and the duration of reflux. ${ }^{12,13}$ Thus, prolonged acid exposure is implicated not only in the metaplastic changes but also in the carcinogenesis of esophageal adenocarcinoma. ${ }^{14}$ Like this study, many reports identified hiatal hernia as a risk factor for erosive esophagitis, CLE, increased lengths of CLE, intestinal metaplasia and esophageal adenocarcinoma. ${ }^{15,16}$ Weaker and proximally displaced lower esophageal sphincter, impaired esophageal acid clearance, and increased esophageal acid exposure had been proposed as the reasons for this risk.

Then, which is better to diagnose Barrett's esophagus between CLE alone and CLE with histologically confirmed intestinal metaplasia? Of course, there is no answer. However, this difference in Barrett's esophagus definition has significant implications for several reasons, giving the patient a diagnosis of pre-malignant lesion, insurance rates, impact on quality of life, the need for endoscopic surveillance, and possibly, endoscopic eradication therapy. Therefore, in a clinical practice, the gastroenterologists should meet the GERD patients after understanding these limitations and ramifications.

In conclusion, this study showed a high prevalence rate of CLE (23.3\%) among GERD patients. Duration of heartburn $>5$ years and presence of hiatal hernia were identified as risk factors for the development of CLE in GERD. These data suggests that defining Barrett's esophagus based upon presence of CLE alone by endoscopy, especially in high-risk groups, would provoke enormous burden on health-care costs and patient surveillance.

\section{References}

1. American Gastroenterological Association, Spechler SJ, Sharma P, Souza RF, Inadomi JM, Shaheen NJ. American Gastroenterological Association medical position statement on the management of Barrett's esophagus. Gastroenterology 2011;140:1084-1091.

2. Bhat $\mathrm{S}$, Coleman HG, Yousef $\mathrm{F}$, et al. Risk of malignant progression in Barrett's esophagus patients: results from a large population-based study. J Natl Cancer Inst 2011;103:1049-1057.

3. Takubo K, Vieth M, Aida J, et al. Differences in the definitions used for esophageal and gastric diseases in different countries: endoscopic definition of the esophagogastric junction, the precursor of Barrett's adenocarcinoma, the definition of Barrett's esophagus, and histologic criteria for mucosal adenocarcinoma or high-grade dysplasia. Digestion 2009;80:248-257.

4. Riddell RH, Odze RD. Definition of Barrett's esophagus: time for a rethink - is intestinal metaplasia dead? Am J Gastroenterol 2009;104: 2588-2594.

5. Wang KK, Sampliner RE; Practice Parameters Committee of the American College of Gastroenterology. Updated guidelines 2008 for the diagnosis, surveillance and therapy of Barrett's esophagus. Am J Gastroenterol 2008;103:788-797.

6. Balasubramanian G, Singh M, Gupta N, et al. Prevalence and predictors of columnar lined esophagus in gastroesophageal reflux disease (GERD) patients undergoing upper endoscopy. Am J Gastroenterol 2012;107:1655-1661.

7. Das D, Ishaq S, Harrison R, et al. Management of Barrett's esophagus in the UK: overtreated and underbiopsied but improved by the introduction of a national randomized trial. Am J Gastroenterol 2008;103:1079-1089.

8. Haggitt RC. Barrett's esophagus, dysplasia, and adenocarcinoma. Hum Pathol 1994;25:982-993.

9. Eloubeidi MA, Provenzale D. Clinical and demographic predictors of Barrett's esophagus among patients with gastroesophageal reflux disease: a multivariable analysis in veterans. J Clin Gastroenterol 2001;33:306-309.

10. Desai TK, Krishnan K, Samala N, et al. The incidence of oesophageal adenocarcinoma in non-dysplastic Barrett's oesophagus: a meta-analysis. Gut 2012;61:970-976.

11. Sharma P, Dent J, Armstrong D, et al. The development and validation of an endoscopic grading system for Barrett's esophagus: the 
Prague C \& M criteria. Gastroenterology 2006;131:1392-1399.

12. Lieberman DA, Oehlke M, Helfand M. Risk factors for Barrett's esophagus in community-based practice. GORGE consortium. Gastroenterology Outcomes Research Group in Endoscopy. Am J Gastroenterol 1997;92:1293-1297.

13. Kulig M, Nocon M, Vieth M, et al. Risk factors of gastroesophageal reflux disease: methodology and first epidemiological results of the ProGERD study. J Clin Epidemiol 2004;57:580-589.

14. Lagergren J, Bergström R, Lindgren A, Nyrén O. Symptomatic gas- troesophageal reflux as a risk factor for esophageal adenocarcinoma. N Engl J Med 1999;340:825-831.

15. Avidan B, Sonnenberg A, Schnell TG, Chejfec G, Metz A, Sontag SJ. Hiatal hernia size, Barrett's length, and severity of acid reflux are all risk factors for esophageal adenocarcinoma. Am J Gastroenterol 2002;97:1930-1936.

16. Cameron AJ. Barrett's esophagus: prevalence and size of hiatal hernia. Am J Gastroenterol 1999;94:2054-2059. 